\title{
lleum terminal antibiotic infusion affects jejunal and colonic specific microbial population and immune status in growing pigs
}

\author{
Chuanjian Zhang, Yu Peng, Chunlong Mu and Weiyun Zhu*
}

\begin{abstract}
Background: Compared with oral antibiotics (primarily disrupt foregut microbiota), the present study used antibiotics with ileum terminal infusion to disrupt the hindgut microbiota, and investigated the changes in specific bacterial composition and immune indexes in the jejunum and colon, and serum of growing pigs. Twelve barrows (45 d of age, $12.08 \pm 0.28 \mathrm{~kg}$ ) fitted with a T-cannula at the terminal ileum, were randomly assigned to two groups and infused either saline without antibiotics (Control) or with antibiotics (Antibiotic) at the terminal ileum. After 25 $\mathrm{d}$ experiment, all pigs were euthanized for analyzing bacterial composition and immune status.
\end{abstract}

Results: lleum terminal antibiotic infusion (ITAI) altered dominant bacteria counts, with a decrease in Bifidobacterium, Clostridium cluster IV and Clostridium cluster IV in the colon $(P<0.05)$, and an increase in Escherichia coli in the jejunum $(P<0.05)$. ITAl decreased $(P<0.05)$ short-chain fatty acids concentrations in the colon. ITAI decreased interleukin-8 (IL-8), IL-10 and secretory immunoglobulin A (slgA) concentrations, and down-regulated IL10, Mucin-1 (MUC1), Mucin-2 (MUC2) and zonula occludens-1 (ZO-1) mRNA expression in the colonic mucosa $(P<0$. 05). In the jejunal mucosa, ITAI decreased interferon- $\gamma(\mathrm{IFN}-\gamma)$, tumor necrosis factor- $a$ (TNF-a), slgA and IgG levels together with down-regulation of IFN- $\gamma$, TNF- $a$, MUC2 and ZO-1 mRNA expression $(P<0.05)$. Furthermore, ITAI decreased IL-10, INF- $\gamma$, TNF- $a$, IgA and IgG concentrations in serum $(P<0.05)$. Correlation analysis revealed that the change in intestinal microbiota was correlated with alterations of $\mathrm{lg}$ and cytokines.

Conclusions: ITAI affected jejunal and colonic specific bacteria counts, and altered some immune markers levels in the jejunal and colonic mucosa and serum. These findings implicate the potential contribution of hindgut bacteria to immune response in the intestinal mucosa and serum of growing pigs.

Keywords: Antibiotic infusion, Growing pigs, Gut bacteria, Immune status, Short-chain fatty acids

\section{Background}

The large intestine of pigs constitutes an environment for the development and activity of the largest microbiota population in the body, which affects the resistance to disease, function of the gastrointestinal tract and health status. Resident bacteria play a pivotal role in development and shaping of the immune system. Loss of diversity and shift in community composition in large intestine may suppress the host's

\footnotetext{
* Correspondence: zhuweiyun@njau.edu.cn

Jiangsu Key Laboratory of Gastrointestinal Nutrition and Animal Health, Laboratory of Gastrointestinal Microbiology, College of Animal Science and Technology, Nanjing Agricultural University, National Center for International Research on Animal Gut Nutrition, Nanjing 210095, China
}

innate immune defense, contributing to disease susceptibility [1]. Meanwhile, microbial metabolites could also affect mucosal immune response [2]. Short-chain fatty acid (SCFA), which are produced mainly from the microbial fermentation of carbohydrates, are considered to be beneficial to the host intestine as they provide energy for epithelial cells, inhibit potential pathogen growth, stimulate epithelial proliferation, facilitate tight junction formation and inhibit inflammation and genotoxicity [3-5]. Furthermore, the immune system affords mammalian hosts some control over the composition of their resident microbial communities [6]. This leads to the idea of the immune system as a form of ecosystem

(c) The Author(s). 2018 Open Access This article is distributed under the terms of the Creative Commons Attribution 4.0 International License (http://creativecommons.org/licenses/by/4.0/), which permits unrestricted use, distribution, and reproduction in any medium, provided you give appropriate credit to the original author(s) and the source, provide a link to the Creative Commons license, and indicate if changes were made. The Creative Commons Public Domain Dedication waiver (http://creativecommons.org/publicdomain/zero/1.0/) applies to the data made available in this article, unless otherwise stated. 
management that exerts critical control over microbiota composition, diversity, and location [7]. Therefore, a symbiotic relationship between the host and the microbiota maintains intestinal homeostasis and prevents intestinal disease.

It is well known that compared to microbiota in the small intestine, microbiota in the hindgut have higher diversity and cell densities [8]. Besides, microbial fermentation in pigs occurs to the largest extent in the hindgut [9]. This enriched microbiota and microbial fermentation products in the hindgut are important to intestinal immune system [10]. Furthermore, previous studies have demonstrated cross-talks between colonic immunity with serum immunity or small intestinal immunity $[11,12]$. Therefore, it is important to understand the effect of hindgut microbiota perturbation on gut (small intestine and large intestine) and serum immunity.

The most profound disrupters of the gut microbiome are antibiotics. Our recent study demonstrated that in feed antibiotics (olaquindox, oxytetracycline calcium and kitasamycin) exerted profound impact on bacteria in the small intestine and less impact on bacteria in colon of piglets [13]. Furthermore, oral chlortetracycline altered ileal microbiota with a decrease in the abundance of Lactobacillus johnsonii, Clostridiales and Turicibacter and an increase in the abundance of Lactobacillus amylovorus [14], but had limited effect on fecal microbiota of pig [15]. These results suggest that in feed antibiotics primarily disrupt the foregut microbiota. Oral antibiotics influenced intestinal and systemic immune parameters [16]. Oral antibiotics reduced mucosal interleukin-17A (IL-17A) and interferon- $\gamma$ (IFN- $\gamma$ ) production by $\mathrm{CD} 4^{+} \mathrm{T}$ lymphocytes in the small intestine [17], and MUC2 mRNA expression in the colon of mice [1, 18]. Oral amoxicillin and clavulanate potassium reduced IgG concentration in the serum of healthy adult humans [19]. Compared with oral antibiotics (primarily disrupt foregut microbiota), the present study used antibiotics with ileum terminal infusion to perturb the hindgut bacteria, to investigate the changes in specific immune responses of gut and serum in pigs. We hypothesized that ileum terminal antibiotic infusion (ITAI) decreased SCFA-producing bacteria counts and SCFA concentration in the colon, which is different from oral antibiotics $[13,20]$. We also hypothesized that ITAI altered some markers of immunity in the intestinal mucosa and serum with a decrease in the levels of specific inflammatory cytokines and immunoglobulins, which is similar to oral antibiotics $[17,19]$. The findings may provide further insights into our understanding of the impact of hindgut microbiota perturbation on gut (small intestine and large intestine) and serum immunity.

\section{Methods}

Animals, housing, diets, surgery and infusions

Twelve 35-day-old growing barrows (Duroc $\times$ Landrace $x$ Large White, weaned at $21 \mathrm{~d}$ with body weight of $10.00 \pm$ $0.5 \mathrm{~kg}$ ) were obtained from a commercial farm in Jiangsu
Province of China. All pigs were fitted with a simple T-cannula in the distal ileum [21] and jugular catheters [22]. After surgery, pigs were housed individually in smooth-sided metabolic crates in a temperature-controlled room at $28{ }^{\circ} \mathrm{C}$ with free access to water and allowed a 10-d recovery period. Pigs were fed increasing amounts of a $19 \%$ crude protein $(\mathrm{CP})$ commercial feed during the 5-d of recovery period. Thereafter, all pigs received the corn-soybean diet formulated based on NRC requirements without any antibiotic cocktail (Table 1) [23]. At d 45 of

Table 1 Composition and analyzed nutrient contents of experimental diets (as-fed basis)

\begin{tabular}{|c|c|}
\hline Item & Content \\
\hline \multicolumn{2}{|l|}{ Ingredient, \% } \\
\hline Corn & 69.17 \\
\hline Soybean meal & 19.40 \\
\hline Soybean protein concentrate & 4.00 \\
\hline Soybean oil & 0.50 \\
\hline Fish meal & 3.00 \\
\hline L-Lysine $\mathrm{HCl}, 98.50 \%$ & 0.35 \\
\hline DL-Methionine & 0.18 \\
\hline L-Threonine & 0.13 \\
\hline L-Tryptophan & 0.02 \\
\hline Stone dust & 0.80 \\
\hline Dicalcium phosphate & 0.75 \\
\hline Sodium chloride & 0.30 \\
\hline Choline chloride & 0.10 \\
\hline Chromic oxide & 0.30 \\
\hline Vitamins and minerals Premix ${ }^{a}$ & 1.00 \\
\hline Total & 100.00 \\
\hline \multicolumn{2}{|l|}{ Calculated composition, \% } \\
\hline $\mathrm{NE}, \mathrm{kcal} / \mathrm{kg}$ & 2554.75 \\
\hline$C P, \%$ & 19.19 \\
\hline $\mathrm{EE}, \%$ & 4.52 \\
\hline$C F, \%$ & 2.15 \\
\hline $\mathrm{Ca}, \%$ & 0.65 \\
\hline$P, \%$ & 0.44 \\
\hline SID ${ }^{\mathrm{b}}$ Lysine & 1.16 \\
\hline SID Methionine & 0.46 \\
\hline SID Tryptophan & 0.21 \\
\hline SID Threonine & 0.71 \\
\hline \multicolumn{2}{|l|}{ Analyzed composition, \% } \\
\hline $\mathrm{CP}$ & 19.10 \\
\hline Fat & 4.28 \\
\hline
\end{tabular}

${ }^{a}$ Supplied the following per $\mathrm{kg}$ of diet: 8,000 IU, vitamin $\mathrm{A} ; 2,400 \mathrm{IU}$, vitamin $\mathrm{D}_{3} ; 20 \mathrm{mg}$, vitamin $\mathrm{E}_{5} 5 \mathrm{mg}$, vitamin $\mathrm{B}_{6} ; 0.03 \mathrm{mg}$, vitamin $\mathrm{B}_{12} ; 15 \mathrm{mg}$, pantothenic acid; $0.3 \mathrm{mg}$, biotin; $3 \mathrm{mg}$, folic acid; $40 \mathrm{mg}$, ascorbic acid; 120 $\mathrm{mg}$, Fe; 25 mg, Cu; 20 mg, Mn; 150 mg, Zn; 0.5 mg, l; 0.30 mg, Se. ${ }^{\mathrm{b}} \mathrm{SID}$ standardized ileal digestible 
age, 12 pigs $(12.08 \pm 0.28 \mathrm{~kg})$ were randomly assigned to 1 of 2 infusion treatment based on equal body weights: 1) control $(n=6)$ receiving infusion of $10 \mathrm{~mL}$ saline solution $(0.9 \% \mathrm{NaCl})$ via T-cannula; 2$)$ antibiotic $(n=6)$ receiving infusion of $10 \mathrm{~mL}$ saline solution with antibiotic (ampicillin, $150(\mathrm{mg} / \mathrm{kg}) / \mathrm{d}$, gentamicin, $4(\mathrm{mg} / \mathrm{kg}) / \mathrm{d}$, and metronidazole, $30(\mathrm{mg} / \mathrm{kg}) / \mathrm{d})$ via T-cannula. Solutions were infused every morning before feeding, and the concentration of the infusion solution was adjusted for every 3-d according to the body weight. Ampicillin is one of $\beta$-lactam antibiotics with activity against Gram-positive and Gram-negative bacteria. Gentamycin exhibits activity mainly against most Gram-negative bacteria and anaerobes. Metronidazole can act against anaerobes. This antibiotic cocktail acts against most bacteria in the gastrointestinal tract of pigs. After $25 \mathrm{~d}$ experiment, all pigs were euthanized. Body weight and feed consumption of individual pigs were recorded from d 45 of age to $\mathrm{d} 70$ of age in order to determine average daily gain (ADG), average daily feed intake (ADFI), and gain to feed ratio (G:F). Blood samples $(10 \mathrm{~mL})$ were collected from the jugular vein of pigs and serum was obtained by centrifuging at $3,000 \times g$ for $10 \mathrm{~min}$ at $4{ }^{\circ} \mathrm{C}$. Thereafter, the serum samples were stored at $-20{ }^{\circ} \mathrm{C}$ for determination of immunoglobulin (Ig) and cytokines. Contents of jejunum and colon were collected and stored at $-80{ }^{\circ} \mathrm{C}$ for later bacterial DNA extraction. In addition, a small piece of gut tissue from middle section of jejunum and colon was excised and rinsed in PBS. The mucosa scrapings were collected by scraping off the mucosa using a sterile glass microscope slide and immediately stored at $-80{ }^{\circ} \mathrm{C}$ for RNA, cytokines and sIgA analyses.

\section{Microbial DNA isolation and real-time qPCR analysis of the bacterial 16S ribosomal RNA gene}

Total genomic DNA was extracted from $300 \mathrm{mg}$ fresh jejunal and colonic luminal contents by using a bead-beating method and phenol-chloroform extraction [24]. The DNA was then precipitated with ethanol and the pellets were dissolved in $80 \mu \mathrm{L}$ of Tris EDTA (TE).

Numbers of total bacteria, Bacteroides-Prevotella, Bifidobacterium, Clostridium cluster IV, Clostridium cluster XIVa, Escherichia coli and Lactobacillus were quantified by real-time polymerase chain reaction (PCR) using specific primers (Table 2) and SYBR Green Premix (Takara Biotechnology, Dalian, China) in the StepOnePlus ${ }^{\mathrm{Tm}}$ Real-Time PCR System (Life Technologies, California, USA). Quantification of $16 \mathrm{~S}$ rRNA gene copies in each sample was performed in triplicate, and the mean value was calculated. Each bacterial group copy number in the jejunum or colon was quantified according to standard curve of bacterial groups which were generated from serial dilutions of the plasmid. For each reference strain, target gene (the 16S rRNA gene) was cloned into a pMD-19 T Vector System (TaKaRa Biotechnology, Dalian, China). An Escherichia coli strain was transformed with the recombinant plasmid, and plasmid DNA was extracted from Escherichia coli by the miniprep method [25].

\section{Short-chain fatty acid in the jejunum and colon}

Jejunal and colonic digesta were prepared for total short-chain fatty acid (SCFA) analysis by mixing $0.4 \mathrm{~g}$ of digesta with $0.2 \mathrm{~mL}$ of $25 \%(w / v)$ metaphosphoric acid and $1.6 \mathrm{~mL}$ of water. The mixture was vortexed and then centrifuged at $13,000 \times g$ for $10 \mathrm{~min}$ at $4{ }^{\circ} \mathrm{C}$. The supernatant was frozen at $-20{ }^{\circ} \mathrm{C}$ and used for SCFA determination [26].

\section{Reverse transcription quantitative PCR analysis of jejunal} and colonic epithelial gene expression

Total RNA was extracted from jejunal and colonic mucosa with using TRIzol reagent (Takara Bio, Otsu, Japan) [27]. The RNA concentration was then quantified using a NanoDrop spectrophotometer (ND-1000UV-Vis; Thermo Fisher Scientific, Waltham, MA), and the absorption ratio (260/280 nm) ranging from 1.8 to 2.0 indicated high RNA purity. Complementary DNA (cDNA) was reverse transcribed from $1 \mu \mathrm{g}$ of eluted RNA by using a PrimeScript ${ }^{\circ}$ RT Reagent Kit with gDNA Eraser (Takara Bio) following the manufacturer's instructions.

Expression levels of toll-like receptor (TLR2, TLR4 and TLR5), intestinal cytokines $[I L-8, I L-10, I F N-\gamma$ and tumor necrosis factor- $\alpha(T N F-\alpha)]$, chemical barrier function (Mucin-1 and Mucin-2) and mechanical barrier function [Occludin and zonula occludens-1 (ZO-1)] were analyzed by real-time quantitative PCR with SYBR Green PCR reagents (TaKaRa), and analyses were performed using the ABI 7300 Real-time PCR system (Applied Biosystems, Foster, CA, USA). The specific primers used in this study were listed below (Table 3). Amplification conditions were as follows: $95{ }^{\circ} \mathrm{C}$ for $30 \mathrm{~s}$, followed by 40 cycles composed of $5 \mathrm{~s}$ at $95{ }^{\circ} \mathrm{C}$ and $30 \mathrm{~s}$ at $60{ }^{\circ} \mathrm{C}$. All measurements were made in triplicate, and the mean threshold cycle was calculated. The results were normalized to the expression of $\beta$-actin gene and relative expression levels were calculated by using the $2^{-\Delta \Delta C t}$ method.

\section{Immunoglobulins and cytokines analyses}

Accordance with the manufacturer's instructions, porcine-specific ELISA kits were used to quantify circulating immunoglobulin (IgA and IgG) (Bethyl Laboratories, Montgomery, TX). Immunoglobulin (sIgA and IgG) in the mucosa and cytokines (IL-8, IL-10, TNF- $\alpha$ and IFN- $\gamma$ ) in the serum and mucosa were measured using commercially available ELISA kits (Beijing 4A BiotechCo., Ltd., Beijing, China) in accordance with the manufacturer's instructions and run in duplicates. Before the assays, the mucosa samples were vortexed in PBS $(1: 10, w / w)$ for $60 \mathrm{~s}$ and centrifuged at $5,000 \times g$ for at $4{ }^{\circ} \mathrm{C}$, and the supernatant was obtained and used for the determination of cytokines and Ig levels. The concentrations of each cytokine and Ig in the intestinal mucosa were 
Table 2 List of primers used in this study

\begin{tabular}{lllll}
\hline Bacteria & Forward primer, $5^{\prime} \rightarrow 3^{\prime}$ & Reverse primer, $5^{\prime} \rightarrow 3^{\prime}$ & Reference & Annealing temp, ${ }^{\circ} \mathrm{C}$ \\
\hline Total bacteria & GTGSTGCAYGGYGTCGTCA & ACGTCRTCCMCNCCTTCCTC & {$[63]$} & 60 \\
Bacteroides-Prevotella & GAGAGGAGGTCCCCCAC & CGCTACTTGGCTGGTTCAG & {$[64]$} & 60 \\
Bifidobacterium & TCGCGTCYGGTGTGAAAG & GGTGTTCTTCCCGATATCTACA & {$[65]$} & 60 \\
Clostridium cluster IV & GCACAAGCAGTGGAGT & CTTCCTCCGTTTGTCAA & {$[66]$} & 60 \\
Clostridium cluster XIVa & CGGTACCTGACTAAGAAGC & AGTTTYTTCTTGCGAACG & {$[67]$} & 60 \\
Escherichia coli & CATGCCGCGTGTATGAAGAA & CGGGTAACGTCAATGAGCAAA & {$[68]$} & 60 \\
Lactobacillus & AGCAGTAGGGATCTTCCA & ATTCCACCGCTACACATG & {$[69]$} & 60 \\
\hline
\end{tabular}

standardized to the protein in each sample. Total protein content in the mucosa was determined with Coomassie blue method following the manufacturer's instructions (Nanjing Jiancheng Bioengineering Institute, Nanjing, China).

\section{Statistical analysis}

Data were analyzed by SPSS 16.0 (SPSS Inc., Chicago, IL, USA) as a randomized block design, considering the antibiotic as main effect and the replicate as a block. The individual pig was used as the experimental unit ( $n$ $=6$ ) of all analysis. Results were statistically analyzed by Student's $t$-test corrected with the false-discovery rate (FDR). All data were expressed as mean \pm SEM, and $P \leq$ 0.05 was considered statistically significant. The $R$ package of "Hmisc" was used for calculating the spearman's correlation coefficient.

\section{Results}

\section{Growth performance}

During the whole experiment period, no clinical signs of diarrhoea or health impairment were observed with all pigs. Average daily gain did not significantly differ $(P>0.05)$ between the antibiotic group and control group (483.26 \pm
57.82 vs. $539.16 \pm 69.50 \mathrm{~g} / \mathrm{d})$. There was no significant difference $(P>0.05)$ in the average daily feed intake between the antibiotic group and control group (952.40 \pm 49.85 vs. $1046.89 \pm 61.58 \mathrm{~g} / \mathrm{d})$. Furthermore, no significant differences $(P>0.05)$ in feed:gain were observed between the antibiotic group and control group $(2.07 \pm 0.18$ vs. $2.08 \pm 0.29)$ (data not shown).

\section{Dominant microbial groups in jejunal and colonic contents}

The results of the effect of ITAI on intestinal dominant microbiota determined by real-time PCR are shown in Fig. 1. Total bacterial counts detected in the jejunum and colon were similar between the antibiotic and control groups. In the jejunum, ITAI significantly increased Escherichia coli counts $(P<0.05)$. However, the counts of Bacteroides-Prevotella, Bifidobacterium, Clostridium cluster IV, Clostridium cluster XIVa and Lactobacillus did not significantly differ between the antibiotic and control groups. In the colon, ITAI significantly decreased $(P<0.05)$ Bifidobacterium, Clostridium cluster IV and Clostridium cluster XIVa counts, but had little effect on Bacteroides-Prevotella, Lactobacillus and Escherichia coli counts. These results

Table 3 Primer pairs for host genes

\begin{tabular}{|c|c|c|c|c|}
\hline Gene $^{a}$ & Forward primer, $5^{\prime} \rightarrow 3^{\prime}$ & Reverse primer, $5^{\prime} \rightarrow 3^{\prime}$ & Reference & Annealing temp, ${ }^{\circ} \mathrm{C}$ \\
\hline$\beta$-actin & AGAGCGCAAGTACTCCGTGT & ACATCTGCTGGAAGGTGGAC & [70] & 60 \\
\hline TLR2 & TCACTTGTCTAACTTATCATCCTCTTG & TCAGCGAAGGTGTCATTATTGC & [71] & 60 \\
\hline TLR4 & TCAGTTCTCACCTTCCTCCTG & GTTCATTCCTCACCCAGTCTTC & [72] & 60 \\
\hline TLR5 & CAGCGACCAAAACAGATTGA & TGCTCACCAGACAGACAACC & [71] & 60 \\
\hline IL-8 & ACTGGCTGT TGCCTTCTT & CAGTT CTCTTCAAAAATATCTG & [73] & 60 \\
\hline IL-10 & GTCCGACTCAACGAAGAAGG & GCCAGGAAGATCAGGCAATA & [70] & 60 \\
\hline IFN- $\gamma$ & TCCAGCGCAAAGCCATCAGTG & ATGCTCTCTGGCCTTGGAACATAGT & [74] & 60 \\
\hline TNF- $a$ & CCACGCTCTTCTGCCTACTGC & GCTGTCCCTCGGCTITGAC & [73] & 60 \\
\hline MUC1 & GGTACCCGGCTGGGGCATTG & GGTAGGCATCCCGGGTCGGA & [70] & 60 \\
\hline MUC2 & CTGCTCCGGGTCCTGTGGGA & CCCGCTGGCTGGTGCGATAC & [70] & 60 \\
\hline OCLN & ATGCTITCTCAGCCAGCG TA & AAG GTTCCATAGCCTCGGTC & [73] & 60 \\
\hline ZO-1 & GAGGATGGTCACACCGTGGT & GGAGGATGCTGTTGTCTCGG & [73] & 60 \\
\hline
\end{tabular}

${ }^{a} T L R 2$ toll-like receptor2, TLR4 toll-like receptor 4, TLR5 toll-like receptor 5, IL-8 interleukin-8, IL-10 interleukin-10, IFN- $\gamma$ interferon- $\gamma$, TNF- $a$ tumor necrosis factor- $a$, ZO-1 zonula occludens-1, MUC1 mucin-1; MUC2 mucin-2; OCLN occludin 


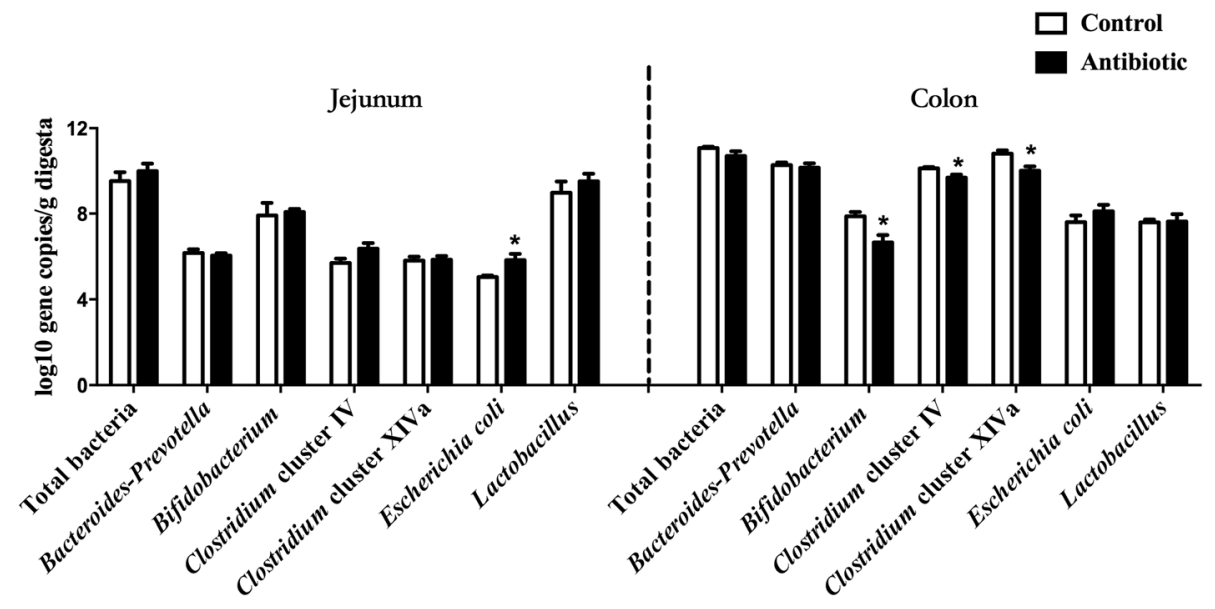

Fig. 1 Effects of ileum terminal antibiotic infusion (ITAI) on copy numbers (Lg [copies/g]) of major bacterial taxonomic groups in the jejunum and colon of pigs. Values are means $\pm \operatorname{SEMs}(n=6)$. Asterisks indicate statistically significant difference from control: ${ }^{*} P<0.05$

indicate that ITAI significantly changed particular bacterial species in growing pigs, with a decrease in the counts of generally beneficial bacteria in the colon and an increase in Escherichia coli counts in the jejunum.

\section{Short chain fatty acid}

The concentrations of SCFAs were measured as indicators of microbial fermentation. In the jejunum, SCFAs were below the limit of detection in both groups (data not shown). In the colon, ITAI significantly decreased $(P<0.05)$ the concentrations of propionate, isobutyrate, butyrate, total SCFA, and tended to decrease $(P=0.054$ and $P=0.075$, respectively) the concentrations of acetate and isovalerate (Table 4). However, valerate concentration did not differ significantly between the antibiotic and control groups. These results indicate that ITAI significantly decreased the production of the beneficial compound SCFA in the colon.

\section{Gene expression analysis in the mucosa of jejunum and colon}

Effects of ITAI on genes expression in jejunal and colonic mucosa are shown in Fig. 2. There was no effect of ITAI on

Table 4 Effects of ileum terminal antibiotic infusion (ITAl) on short chain fatty acid (SCFA) concentrations in colon of pigs ${ }^{a}$

\begin{tabular}{llll}
\hline Item $^{\mathrm{b}}, \mu \mathrm{mol} / \mathrm{g}$ digesta & Control & Antibiotic & $P$-value \\
\hline Acetate & $65.68 \pm 5.83$ & $48.76 \pm 5.08$ & 0.054 \\
Propionate & $27.71 \pm 2.62$ & $19.32 \pm 2.09$ & 0.031 \\
Isobutyrate & $0.64 \pm 0.10$ & $0.33 \pm 0.08$ & 0.034 \\
Butyrate & $9.33 \pm 0.88$ & $4.06 \pm 1.06$ & 0.003 \\
Isovalerate & $1.04 \pm 0.18$ & $0.64 \pm 0.07$ & 0.075 \\
Valerate & $1.14 \pm 0.10$ & $0.62 \pm 0.29$ & 0.115 \\
Total SCFA & $105.55 \pm 8.26$ & $73.73 \pm 7.06$ & 0.015 \\
\hline
\end{tabular}

avalues are mean \pm SEMs; $n=6$ /group

${ }^{\mathrm{b}}$ Total SCFA $=$ total short-chain fatty acid
mRNA expression of innate immune receptors (TLR2, TLR4 and TLR5) in the mucosa of jejunum and colon. For pro-inflammatory cytokines $(I L-8, I F N-\gamma$ and TNF- $\alpha)$ and anti-inflammatory cytokines $(I L-10)$, in the jejunal mucosa, ITAI significantly decreased $(P<0.05) I F N-\gamma$ and $T N F-\alpha$ mRNA expression, while mRNA expression of $I L-8$ and $I L-10$ remained similar in both experimental groups. In the colonic mucosa, $I L-10$ mRNA expression was significantly decreased in response to the antibiotics $(P<0.05)$. However, no significant changes of $I L-8, I F N-\gamma$ and TNF- $\alpha$ gene expression measured by qRT-PCR were recorded between the antibiotic and control groups. For chemical barrier function (Mucin-1 and Mucin-2) and mechanical barrier function (Occludin and ZO-1), in the jejunal mucosa, no differences in the mRNA expression of $M U C 1$ and OCLN were observed between the antibiotic and control groups, but ITAI significantly decreased $(P<0.05) M U C 2$ and $Z O-1$ mRNA expression. In the colonic mucosa, the mRNA expression of $M U C 1, M U C 2$ and $Z O-1$ originating from the antibiotic group were significantly decreased $(P<0.05)$ compared to control group. These results indicate that ITAI down-regulated specific genes involved in intestinal immunity, with different effect between jejunum and colon.

\section{Immunoglobulin and cytokines concentrations in the mucosa of jejunum and colon}

The results of the effects of ITAI on jejunal and colonic Ig and cytokines concentrations by ELISA are shown in Fig. 3. For cytokines (IL-8, IL-10, IFN- $\gamma$ and TNF- $\alpha$ ), in the jejunum, IFN- $\gamma$ and TNF- $\alpha$ concentrations originating from the antibiotic group were significantly decreased compared to control group $(P<0.05$, Fig. 3a). However, no significant differences in IL-8 and IL-10 concentrations were observed between the antibiotic and control groups. In the colon, ITAI significantly decreased IL-8 and IL-10 concentrations $(P<0.05)$, but had little effect on IFN- $\gamma$ and TNF- $\alpha$ 


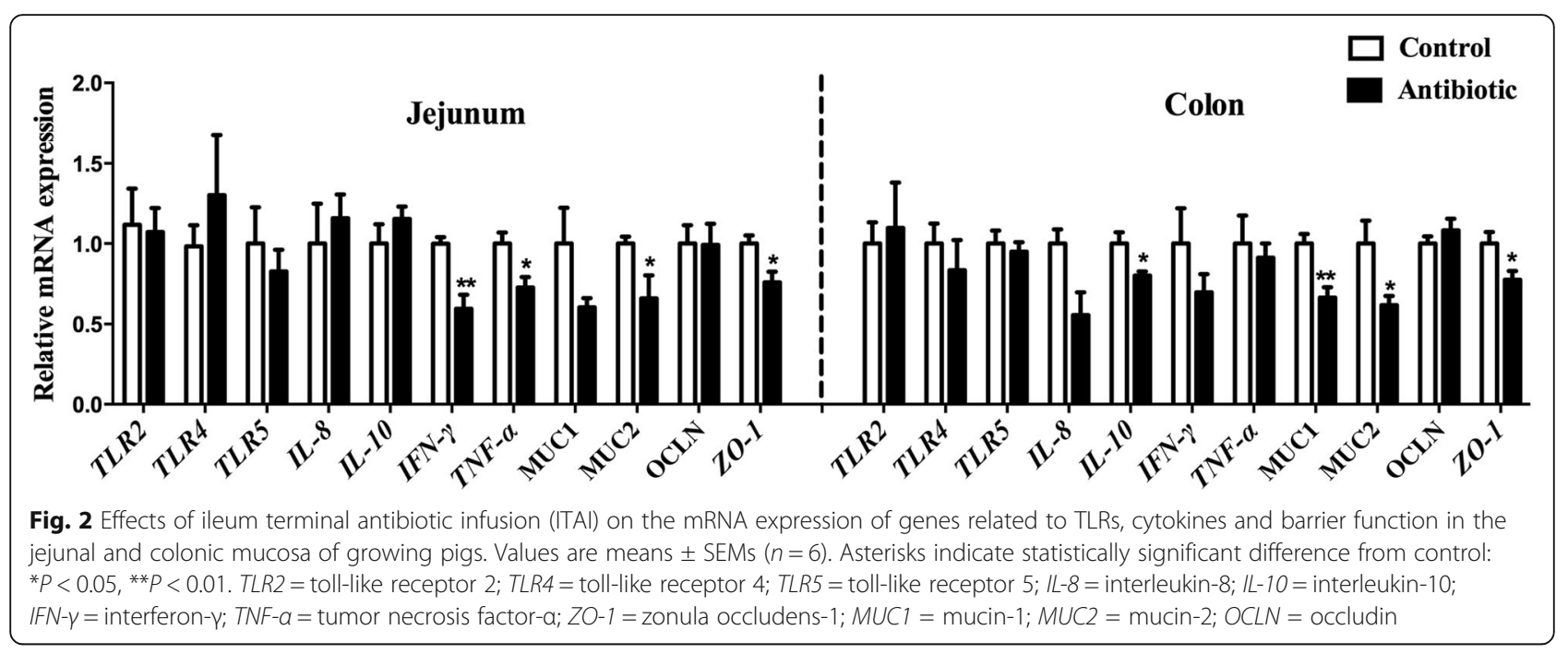

concentrations (Fig. 3b). For Ig (sIgA and IgG), in the jejunum, ITAI significantly decreased $(P<0.05)$ sIgA and IgG concentrations (Fig. 3a). In the colon, the concentration of sIgA from the antibiotic group was significantly decreased $(\mathrm{P}<0.05)$ compared to control group (Fig. 3b). These results suggest that ITAI affected jejunal and colonic mucosal immune responses with a decrease in specific cytokines and Igs concentrations.

Immunoglobulin and cytokines concentrations in plasma To understand the effects of ITAI on the systemic immune response, serum cytokines and Igs concentrations were determined by ELISA (Fig. 4). For cytokines, ITAI
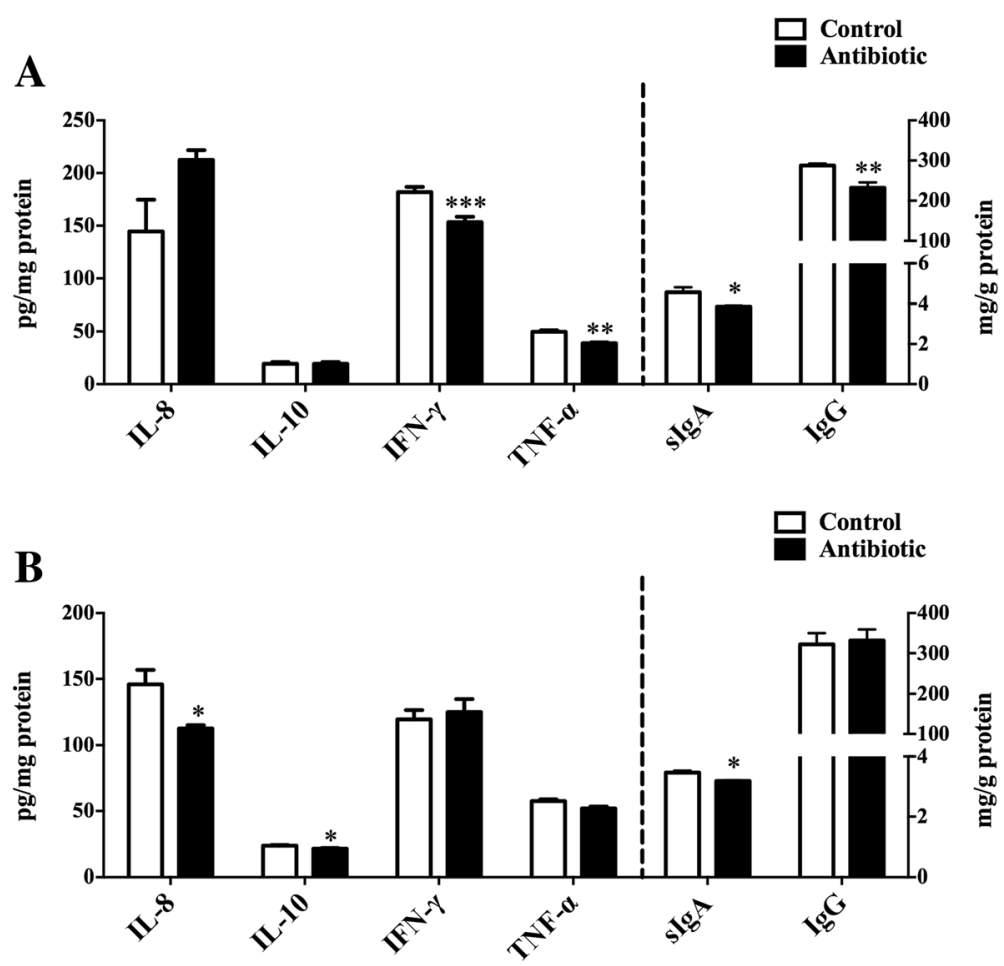

Fig. 3 Effect of ileum terminal antibiotic infusion (ITAI) on the concentrations of intestinal cytokines and immunoglobulins in the jejunum (a) and colon (b) of pigs. Values are means \pm SEMs $(n=6)$. Asterisks indicate statistically significant difference from control: ${ }^{*} P<0.05,{ }^{* *} P<0.01,{ }^{* * *} P<0.001$. IL-8 = interleukin-8; IL-10 = interleukin-10; IFN- $\gamma=$ interferon- $-;$ TNF- $a=$ tumor necrosis factor-a; slgA = secretory immunoglobulin A; $\lg \mathrm{G}=$ immunoglobulin $\mathrm{G}$ 


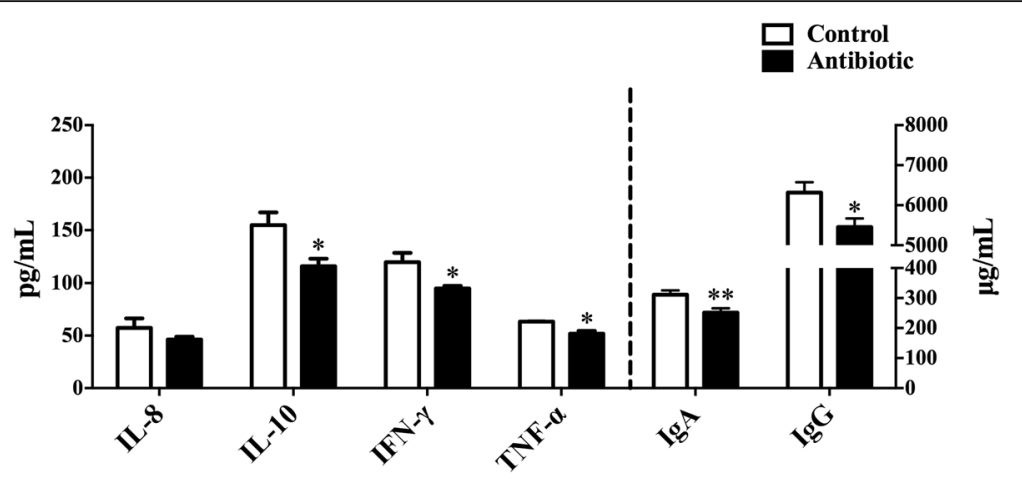

Fig. 4 Effect of ileum terminal antibiotic infusion (ITAI) on the concentrations of serum cytokines and immunoglobulins in plasma of growing pigs. Values are means \pm SEMs $(n=6)$. Asterisks indicate statistically significant difference from control: ${ }^{*} P<0.05,{ }^{* *} P<0.01$. IL-8 $=$ interleukin-8; IL-10 = interleukin-10; IFN- $\gamma=$ interferon- $\gamma$; TNF- $-\mathrm{a}=$ tumor necrosis factor- - ; $\lg A=$ immunoglobulin $A ; \operatorname{lgG}=$ immunoglobulin $\mathrm{G}$

significantly decreased $(P<0.05)$ IL-10, IFN- $\gamma$ and TNF- $\alpha$ concentrations, while IL- 8 concentration remained similar in both experimental groups. Pigs in the antibiotic group recorded lower $(P<0.05)$ IgG and IgA concentrations. These results suggest that ITAI affected serum immune responses with a decrease in serum specific cytokines and Igs concentrations in growing pigs.

\section{Correlation analysis of immune markers levels in the jejunal and colonic mucosa and serum, dominant microbial communities counts in the jejunum and colon and SCFA concentration in the colon}

The correlation analysis of all measured bacterial taxa counts, immune parameters levels and SCFA concentration has been shown in Fig. 5. The scatterplots of some correlations were shown in the Additional file 1: Figure S1. The correlation analysis revealed that Clostridium cluster IV and Clostridium cluster XIVa counts were positively correlated $(P<0.05)$ with butyrate concentration in the colon. Clostridium cluster IV and Clostridium cluster XIVa counts in the colon were positively correlated $(P<0.05)$ with colonic IL-10 and sIgA concentrations, serum IL-10, IgA and IgG and jejunal sIgA. Clostridium cluster XIVa counts in the colon were positively correlated $(P<0.05)$ with jejunal TNF- $\alpha$ and IgG concentrations. Bifidobacterium counts in the colon were positively correlated $(P<0.05)$ with colonic IL-10 and sIgA concentrations and serum IL-10, IgA and IgG. Butyrate concentration was positively correlated $(P<$ 0.05 ) with mRNA expression levels of Mucin-1 and Mucin-2 in the colon. Colonic SIgA and IL-10 concentrations showed positive correlations $(P<0.05)$ with serum IgA, IgG, IL-10 and TNF- $\alpha$ concentrations, and jejunal sIgA concentration. In the jejunum, the counts of Escherichia coli were negatively correlated $(P<0.05)$ with the concentrations of IgG and TNF- $\alpha$. These results suggest that the changes in intestinal microbiota are correlated with alterations of Ig and cytokines concentrations. Furthermore, colonic Ig and cytokines were correlated with serum and jejunal Ig and cytokines.

\section{Discussion}

Previous studies have shown that oral antibiotics may cause gut microbiota dysbiosis, suppress the innate immune defenses, and lead to the increased pathogen colonization and disease susceptibility in mice [18, 28, 29]. For the first time, to our knowledge, the current experiment evaluating the effect of ITAI on specific bacterial composition and mucosal immune response in the jejunum and colon, and serum immune index of pigs. Our findings suggest that ITAI affected specific bacteria in the colon, and altered some markers of immunity in the colon, serum and jejunum, which may increase opportunities for Escherichia coli to colonize in the jejunum.

The present study showed that ITAI significantly changed the specific intestinal bacteria, with a decrease in generally beneficial bacteria (Bifidobacterium, Clostridium cluster IV and Clostridium cluster XIVa) in the colon and an increase in Escherichia coli in the jejunum (Fig. 1). Bifidobacterium is reported to be a health-promoting bacterium and potential probiotic [30]. One of the most important functions of Bifidobacterium is to reduce TLR4 signalling by competing for nutrients and adhesion site with gram-negative pathogens, and then promoting the intestinal mucosal barrier function and regulating intestinal immunity [31, 32]. Butyrate-producing bacteria, such as Clostridium cluster IV and Clostridium cluster XIVa, together with butyrate, could benefit colonic homeostasis by promoting epithelial energy metabolism and modulating immune development [33]. In the present study, another finding was that ITAI increased Escherichia coli counts in the jejunum (Fig. 1). The increase in Escherichia coli has been shown to be associated with the development of Crohn's disease [34]. However, the exact cause of higher Escherichia coli counts in the 


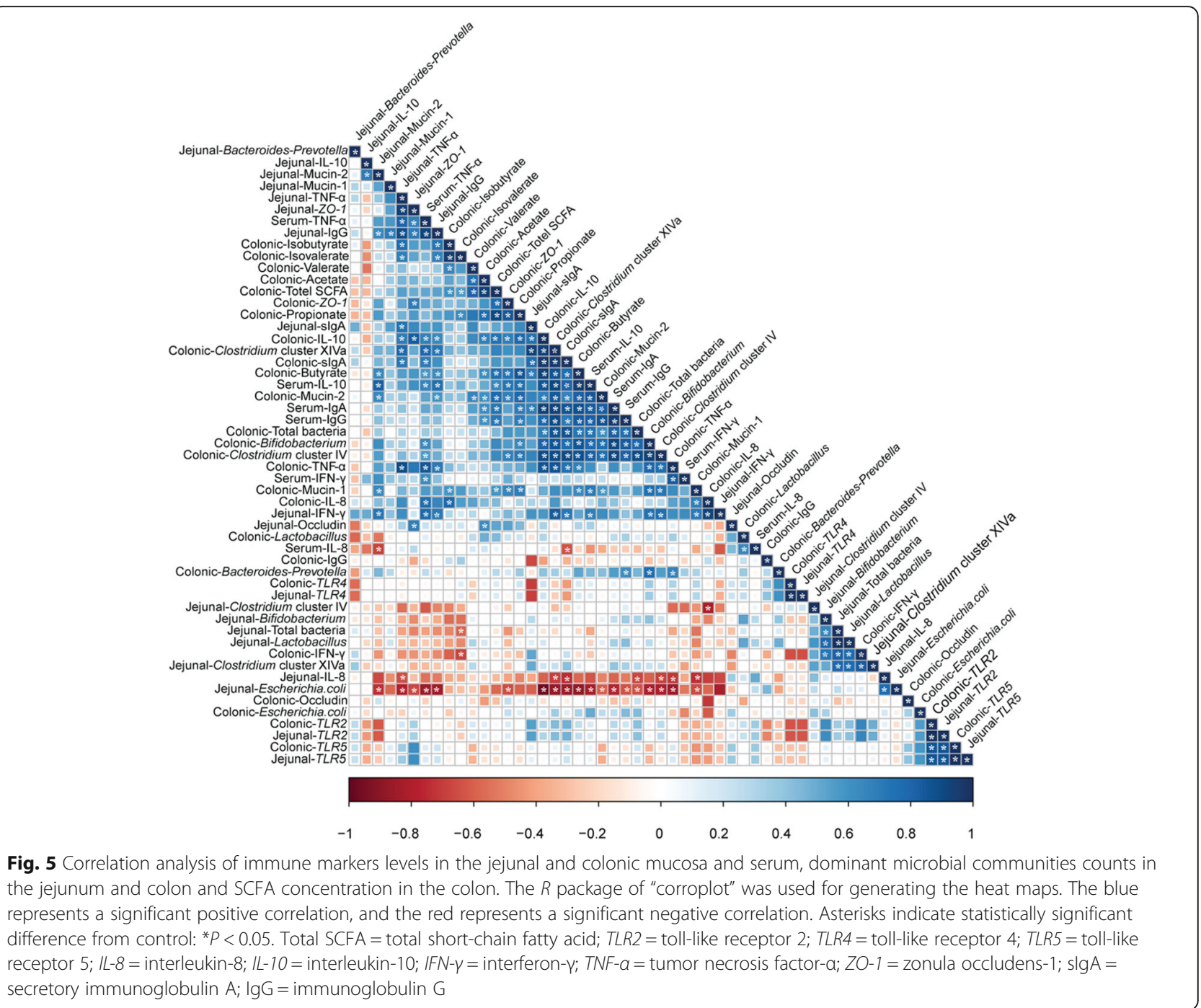

antibiotic group compared with control group is not clear. Many studies have shown that exposure to antibiotics can cause gut microbiota dysbiosis and inflammatory bowel disease $[35,36]$. The loss of bacterial ligands, alterations in the metabolites and the loss of specific bacterial signals with antibiotic treatment may induce changes of immune function, leading to increased pathogen colonization and disease susceptibility [37]. A previous study showed that treatment with oral metronidazole affects the expression of Mucin-2, reduces the integrity of the mucous layer and increases mucosal attachment of Citrobacter rodentium in the colon of rats [1]. Therefore, in the present study, ITAI may affect gut immunity, leading to a vulnerable gut environment which could be susceptible to pathogen colonization and disease. A significant negative correlation between the concentrations of IgG and TNF- $\alpha$ and the counts of Escherichia coli (Fig. 5) suggests that there may be the potential causal relation between the increase in Escherichia coli and the change in immune system in the jejunal mucosa.
The three major SCFAs acetate, propionate and butyrate are main end products from carbohydrates fermentation, and are less produced from amino acids in hindgut, while branched chain fatty acids (BCFAs) (i.e., isobutyrate and isovalerate) originate exclusively from the breakdown of protein $[38,39]$, and represent good markers of protein breakdown in hindgut. In the present study, ITAI decreased SCFA concentration in the colon (Table 4), especially propionate and butyrate. SCFA create a slightly acidic environment, thereby preventing the growth of acid-sensitive detrimental bacteria, including pathogenic Salmonella and Escherichia coli [40]. Butyrate is a major energy source for colonocytes [41]. Furthermore, propionate and butyrate exert an anti-inflammatory function [42, 43], which are vital in maintaining gut tolerance. The low propionate and butyrate concentrations in the antibiotic group may not benefit gut health. We also found antibiotic infusion decreased the concentrations of isobutyrate and isovalerate concentrations (Table 4). It suggests that 
ITAI may decrease incomplete degradation of amino acids (especially leucine and valine) or BCFA-producing bacteria counts in the colon. A previous study indicates that BCFAs may be able to promote intestinal integrity [44].

Intestinal microbiota and its metabolites could affect systemic and intestinal immunity. In the present study, ITAI decreased intestinal pro-inflammatory cytokines levels, such as IL-8 in the colonic mucosa, IFN- $\gamma$ and TNF- $\alpha$ in the serum and jejunal mucosa (Figs. 2, 3 and 4). Previous studies have revealed pro-inflammatory cytokines, whose expression was affected by intestinal commensal bacteria, play a central role in intestinal inflammatory disease [45, 46]. Anti-inflammatory cytokines, such as IL-10 and IL-4, prevent over-activation of immune response and suppress the production of pro-inflammatory cytokines to maintain immune homeostasis [47]. At present, we observe that ITAI decreased IL-10 level in the colon (Figs. 2 and 3). A previous study reported that colonization with a mixture of Clostridium species from clusters IV and XIVa can suppress colitis through the induction of IL-10-producing regulatory $\mathrm{T}$ (Treg) cells [48]. A significant positive correlation between IL-10 expression and the counts of Clostridium clusters IV and XIVa in the colon (Fig. 5) indicates that the reduction in the counts of Clostridium clusters IV and XIVa may partly contribute to the changes in the colonic IL-10 level in the antibiotic group. Cytokines play a crucial role in the immune and inflammatory responses, and their balance is important for protection against infection [49]. Previous studies showed that several cytokine knockout models in mice failed to resist pathogen infection $[50,51]$. In the present study, the reduced pro-inflammatory and anti-inflammatory cytokine with antibiotic treatment may increase susceptibility to infection by pathogens.

The intestinal barrier is mainly formed by a layer of epithelial cells joined together by tight junctions. It acts as a critical line of defense against pathogenic agents and luminal antigens [52]. In the present study, downregulation of intestinal barrier genes expression in the jejunal and colonic mucosa, such as $M U C 1, M U C 2$ and $Z O-1$ (Fig. 2) suggest that ITAI may decrease the integrity of the mucous layer, consequently generating a vulnerable gut environment which could be susceptible to pathogen infection. However, the underlying mechanism of intestinal barrier genes downregulation is unknown. A previous study has shown that antibiotic treatment led to the loss of normal microbiota subsets, thus reducing epithelial exposure to microbiota-derived microorganism-associated molecular patterns (MAMPs). Fewer MAMPs with antibiotic intervention resulted in the decreased pattern recognition receptors stimulation [37], which may lead to the decreased intestinal barrier function and integrity. Furthermore, butyrate, the most extensively studied SCFA, has been shown to maintain the gut integrity [53]. A correlation analysis revealed that butyrate concentration was positively correlated with mRNA expression levels of $M U C 1$ and $M U C 2$. Therefore, the low butyrate concentration in the antibiotic group may also lead to downregulation of intestinal barrier genes expression. However, histology and immunohistochemistry are still needed to validate down-regulation of intestinal barrier genes further.

ITAI also decreased systemic and intestinal Ig concentrations. The present study identified a decrease in the concentrations of $\operatorname{sg} \mathrm{A}$ and $\operatorname{IgG}$ in the jejunal mucosa and $\operatorname{sg} \mathrm{A}$ in the colonic mocosa in the antibiotics group (Fig. 3). Secretory immunoglobulin A, secreted by plasma cells existing in intestinal lamina propria, forms a major component of the local immune barrier of the intestine and plays an integral role in intestinal protection [54]. Therefore, the level of $\operatorname{sg} \mathrm{A}$ in the intestine was used as an indicator to evaluate intestinal mucosal immunity. In addition, IgG also participates in the process of intestinal immune response $[55,56]$. The low concentrations of intestinal Igs in the antibiotic group may indicate a decrease in defensive capacity of the mucosal immune system. ITAI also decreased IgG and IgA concentrations in the serum (Fig. 4). Actually, IgG and IgA are key components of the humoral immunity in all mammals, which are the major serum immunoglobulins that protect the extravascular compartment against microorganisms [57]. Lower IgG and IgA concentrations in serum of the antibiotic group may indicate a decrease in humoral immunity. A previous study reported that Bifidobacterium can induce systemic and intestinal IgA production $[58,59]$. Furthermore, as shown by gnotobiotic studies, the production of IgA is stimulated by the colonization of clostridia [60].Correlation analysis revealed a correlation between colonic sIgA and serum IgA level and the counts of Bifidobacterium and Clostridium clusters IV and XIVa in the colon (Fig. 5), suggesting that the decrease in colonic sIgA and serum IgA level in the antibiotic group may partly be due to the change in the counts of Bifidobacterium and Clostridium clusters IV and XIVa. ITAI caused similar innate immune-related responses as those observed in other models of antibiotic-induced dysbiosis [61]. These changes may represent a general adaptive pattern of the host in response to alterations in the composition of the microbiota.

However, why ITAI affected immune system in the jejunal mucosa is not clear. Correlation analysis revealed that colonic immunoglobulins and cytokines were correlated with serum and jejunal Ig and cytokines. These results indicate that the change in immunity in the colon may partly result in alteration of immune system in the jejunum. As mentioned earlier, in rat models of acute and chronic colitis, increased levels of pro-inflammatory cytokines were demonstrated in distant and intact segments of the small intestine without any significant histological changes [62].

In the present study, IATI directly disrupted the hindgut bacteria, reducing SCFA-produing bacteria counts and SCFA 
concentration in the colon. Our previous studies showed that oral antibiotics had limited effects on microbiota and SCFA concentration in the large intestine $[13,20]$. This may be due to the gradual dilution of antibiotics in the gut, which led to the weakened effects. Oral antibiotics or ITAI may induce the loss of bacterial ligands, alterations in the metabolites and the loss of specific bacterial signals, altering immune response with a decrease in the levels of specific inflammatory cytokines, gene expression and immunoglobulins in the intestinal mucosa and serum.

\section{Conclusions}

ITAI affected specific jejunal and colonic microbial population and immune status, and serum immune index. ITAI increased Escherichia coli counts in the jejunum, while reducing generally beneficial bacteria counts in the colon; Moreover, ITAI affected intestinal and systemic immunity, as evidenced by a decrease in the levels of specific inflammatory cytokines and immunoglobulins in the intestinal mucosa and serum. Correlation analysis revealed that the change in intestinal microbiota was correlated with alterations of Igs and cytokines concentrations. Compared with oral antibiotics (primarily disrupt foregut microbiota), the findings aided in understanding of the impact of ITAI (disrupts hindgut microbiota) on gut and systemic immune in growing pigs.

\section{Additional files}

Additional file 1: Figure S1. Scatterplots demonstrating correlations of some immune markers levels in the jejunal and colonic mucosa and serum, dominant microbial communities counts in the jejunum and colon and butyrate concentration in the colon. $/ L-8=$ interleukin-8; $/ L-10=$ interleukin-10; IFN- $\gamma=$ interferon- $\gamma ;$ TNF- $\alpha=$ tumor necrosis factor- $\alpha$; $s$ lgA $=$ secretory immunoglobulin A; lgG = immunoglobulin G. (DOCX 1289 kb)

\section{Abbreviations}

IFN- $\gamma$ : Interferon- $\gamma$; IL: Interleukin; ITAI: Ileum terminal antibiotic infusion; MUC1: Mucin-1; MUC2: Mucin-2; OCLN: Occludin; SCFA: Short-chain fatty acid; slgA: Secretory immunoglobulin A; TLR: Toll-like receptor; TNF-a: Tumor necrosis factor-a; ZO-1: Zonulaoccludens-1

\section{Acknowledgements}

WYZ thanks Jiangsu Collaborative Innovation Center of Meat Production and Processing, Quality and Safety Control for support.

\section{Funding}

This study was supported by Natural Science Foundation of China (31430082) and National Key Basic Research Program of China, 973 Program (2013CB127300).

\section{Availability of data and materials}

The datasets supporting the conclusions of this article are included within the article.

\section{Authors' contributions}

The author' contributions are as follows: WYZ was in charge of the whole trial; CJZ, CLM and YZW wrote the manuscript; YP for animal feeding and care; All authors read and approved the final manuscript.

\section{Ethics approval and consent to participate}

The experimental proposals and procedures for the care and treatment of the pigs were approved by the Animal Care and Use Committee of Nanjing Agricultural University and followed Chinese guidelines for animal welfare.

\section{Competing interests}

The authors declare that they have no competing interests.

Received: 26 September 2017 Accepted: 17 May 2018

Published online: 02 July 2018

\section{References}

1. Wlodarska M, Willing B, Keeney KM, Menendez A, Bergstrom KS, Gill N, et al. Antibiotic treatment alters the colonic mucus layer and predisposes the host to exacerbated Citrobacter rodentium-induced colitis. Infect Immun 2011;79:1536-45.

2. Rooks MG, Garrett WS. Gut microbiota, metabolites and host immunity. Nat Rev Immunol. 2016;16:341-52.

3. Brown AJ, Goldsworthy SM, Barnes AA, Eilert MM, Tcheang L, Daniels D, et al. The orphan G protein-coupled receptors GPR41 and GPR43 are activated by propionate and other short chain carboxylic acids. J Biol Chem. 2003;278:11312-9.

4. Peng L, Li ZR, Green RS, Holzman IR, Lin J. Butyrate enhances the intestinal barrier by facilitating tight junction assembly via activation of AMP-activated protein kinase in Caco-2 cell monolayers. J Nutr. 2009;139:1619-25.

5. Rist VT, Weiss E, Eklund M, Mosenthin R. Impact of dietary protein on microbiota composition and activity in the gastrointestinal tract of piglets in relation to gut health: a review. Animal. 2013;7:1067-78.

6. Palm NW, de Zoete MR, Flavell RA. Immune-microbiota interactions in health and disease. Clin Immunol. 2015:159:122-7.

7. Hooper LV, Littman DR, Macpherson AJ. Interactions between the microbiota and the immune system. Science. 2012;336:1268-73.

8. O'Hara AM, Shanahan F. The gut flora as a forgotten organ. EMBO Rep. 2006;7:688-93.

9. Williams BA, Verstegen MW, Tamminga S. Fermentation in the large intestine of single-stomached animals and its relationship to animal health. Nutr Res Rev. 2001;14:207-28.

10. Sommer F, Backhed F. The gut microbiota-masters of host development and physiology. Nat Rev Microbiol. 2013;11:227-38.

11. Jonefjall B, Ohman L, Simren M, Strid H. IBS-like symptoms in patients with ulcerative colitis in deep remission are associated with increased levels of serum cytokines and poor psychological well-being. Inflamm Bowel Dis. 2016;22:2630-40.

12. Mourad FH, Barada KA, Saade NE. Impairment of small intestinal function in ulcerative colitis: role of enteric innervation. J Crohns Colitis. 2017;11:369-77.

13. Mu C, Yang Y, Su Y, Zoetendal EG, Zhu W. Differences in microbiota membership along the gastrointestinal tract of piglets and their differential alterations following an early-life antibiotic intervention. Front Microbiol. 2017:8:797.

14. Rettedal E, Vilain S, Lindblom S, Lehnert K, Scofield C, George S, et al. Alteration of the ileal microbiota of weanling piglets by the growth-promoting antibiotic chlortetracycline. Appl Environ Microbiol. 2009;75:5489-95.

15. Poole TL, Suchodolski JS, Callaway TR, Farrow RL, Loneragan GH, Nisbet DJ. The effect of chlortetracycline on faecal microbial populations in growing swine. J Glob Antimicrob Resist. 2013;1:171-4.

16. Ubeda C, Pamer EG. Antibiotics, microbiota, and immune defense. Trends Immunol. 2012;33:459-66.

17. Hill DA, Hoffmann C, Abt MC, Du Y, Kobuley D, Kirn TJ, et al. Metagenomic analyses reveal antibiotic-induced temporal and spatial changes in intestinal microbiota with associated alterations in immune cell homeostasis. Mucosal Immunol. 2010;3:148-58.

18. Jin $Y$, Wu Y, Zeng Z, Jin C, Wu S, Wang Y, et al. From the cover: exposure to oral antibiotics induces gut microbiota dysbiosis associated with lipid metabolism dysfunction and low-grade inflammation in mice. Toxicol Sci. 2016:154:140-52.

19. Dufour $V$, Millon $L$, Faucher JF, Bard $E$, Robinet $E$, Piarroux $R$, et al. Effects of a short-course of amoxicillin/clavulanic acid on systemic and mucosal immunity in healthy adult humans. Int Immunopharmacol. 2005:5:917-28.

20. Mu C, Yang Y, Yu K, Yu M, Zhang C, Su Y, et al. Alteration of metabolomic markers of amino-acid metabolism in piglets with in-feed antibiotics. Amino Acids. 2017:49:771-81.

21. Stein $\mathrm{HH}$, Shipley CF, Easter RA. Technical note: a technique for inserting a T-cannula into the distal ileum of pregnant sows. J Anim Sci. 1998;76:1433-6. 
22. Columbus DA, Lapierre $H$, Htoo JK, de Lange CF. Nonprotein nitrogen is absorbed from the large intestine and increases nitrogen balance in growing pigs fed a valine-limiting diet. J Nutr. 2014;144:614-20.

23. NRC. Nutrient requirements of swine. 11th ed. Washington, DC: Natl Acad Press; 2012.

24. Zoetendal EG, Akkermans AD, De Vos WM. Temperature gradient gel electrophoresis analysis of 165 rRNA from human fecal samples reveals stable and host-specific communities of active bacteria. Appl Environ Microbiol. 1998;64:3854-9.

25. Chowdhury K. One-step miniprep method for the isolation of plasmid DNA. Nucleic Acids Res. 1991;19:2792.

26. Wang XF, Mao SY, Liu JH, Zhang LL, Cheng YF, Jin W, et al. Effect of the gynosaponin on methane production and microbe numbers in a fungusmethanogen co-culture. J Anim Feed Sci. 2011;20:272-84.

27. Chomczynski P, Sacchi N. Single-step method of RNA isolation by acid guanidinium thiocyanate-phenol-chloroform extraction. Anal Biochem. 1987;162:156-9.

28. Willing BP, Vacharaksa A, Croxen M, Thanachayanont T, Finlay BB. Altering host resistance to infections through microbial transplantation. PLoS One. 2011;6:e26988.

29. Brandl K, Plitas G, Mihu CN, Ubeda C, Jia T, Fleisher M, et al. Vancomycinresistant enterococci exploit antibiotic-induced innate immune deficits. Nature. 2008;455:804-7.

30. Tojo R, Suarez A, Clemente MG, de los Reyes-Gavilan CG, Margolles A, Gueimonde $M$, et al. Intestinal microbiota in health and disease: role of Bifidobacteria in gut homeostasis. World J Gastroentero. 2014;20:15163-76.

31. Ohland CL, Macnaughton WK. Probiotic bacteria and intestinal epithelial barrier function. Am J Physiol Gastr L. 2010;298:G807-19.

32. Fooks $L$, Gibson GR. Probiotics as modulators of the gut flora. Brit J Nutr. 2002;88(Suppl 1):S39-49

33. Kaiko GE, Stappenbeck TS. Host-microbe interactions shaping the gastrointestinal environment. Trends Immunol. 2014;35:538-48.

34. Barnich N, Carvalho FA, Glasser AL, Darcha C, Jantscheff $P$, Allez M, et al. CEACAM6 acts as a receptor for adherent-invasive E. coli, supporting ileal mucosa colonization in Crohn disease. J Clin Invest. 2007;117:1566-74.

35. Cho I, Yamanishi S, Cox L, Methe BA, Zavadil J, Li K, et al. Antibiotics in early life alter the murine colonic microbiome and adiposity. Nature. 2012;488:621-6.

36. Boursi B, Mamtani R, Haynes K, Yang YX. The effect of past antibiotic exposure on diabetes risk. Eur J Endocrinol. 2015;172:639-48.

37. Willing BP, Russell SL, Finlay BB. Shifting the balance: antibiotic effects on host-microbiota mutualism. Nat Rev Microbiol. 2011:9:233-43.

38. Rasmussen HS, Holtug K, Mortensen PB. Degradation of amino acids to short-chain fatty acids in humans. An in vitro study. Scand J Gastroenterol. 1988;23:178-82

39. Geypens B, Claus D, Evenepoel P, Hiele M, Maes B, Peeters M, et al. Influence of dietary protein supplements on the formation of bacterial metabolites in the colon. Gut. 1997;41:70-6.

40. Wells JE, Yen JT, Miller DN. Impact of dried skim milk in production diets on Lactobacillus and pathogenic bacterial shedding in growing-finishing swine. J Appl Microbiol. 2005:99:400-7.

41. Donohoe DR, Garge N, Zhang X, Sun W, O'Connell TM, Bunger MK, et al. The microbiome and butyrate regulate energy metabolism and autophagy in the mammalian colon. Cell Metab. 2011;13:517-26.

42. Tedelind S, Westberg F, Kjerrulf M, Vidal A. Anti-inflammatory properties of the short-chain fatty acids acetate and propionate: a study with relevance to inflammatory bowel disease. World J Gastroenterol. 2007;13:2826-32.

43. Bordonaro M, Lazarova DL, Sartorelli AC. Butyrate and Wnt signaling: a possible solution to the puzzle of dietary fiber and colon cancer risk? Cell Cycle. 2008;7:1178-83.

44. Liu H, Zhang J, Zhang S, Yang F, Thacker PA, Zhang G, et al. Oral administration of Lactobacillus fermentum 15007 favors intestinal development and alters the intestinal microbiota in formula-fed piglets. J Agric Food Chem. 2014;62:860-6.

45. Bergstrom A, Kristensen MB, Bahl MI, Metzdorff SB, Fink LN, Frokiaer H, et al. Nature of bacterial colonization influences transcription of mucin genes in mice during the first week of life. BMC Res Notes. 2012:5:402.

46. Gyires K, Toth EV, Zadori SZ. Gut inflammation: current update on pathophysiology, molecular mechanism and pharmacological treatment modalities. Curr Pharm Des. 2014:20:1063-81.

47. Opal SM, DePalo VA. Anti-inflammatory cytokines. Chest. 2000;117:1162-72.

48. Atarashi K, Tanoue T, Shima T, Imaoka A, Kuwahara T, Momose Y, et al. Induction of colonic regulatory T cells by indigenous Clostridium species. Science. 2011;331:337-41.
49. Praveena PE, Periasamy S, Kumar AA, Singh N. Cytokine profiles, apoptosis and pathology of experimental Pasteurella multocida serotype A1 infection in mice. Res Vet Sci. 2010;89:332-9.

50. Nauciel C, Espinasse-Maes F. Role of gamma interferon and tumor necrosis factor alpha in resistance to Salmonella typhimurium infection. Infect Immun. 1992;60:450-4.

51. Kamijo R, Le J, Shapiro D, Havell EA, Huang S, Aguet M, et al. Mice that lack the interferon-gamma receptor have profoundly altered responses to infection with Bacillus Calmette-Guerin and subsequent challenge with lipopolysaccharide. J Exp Med. 1993;178:1435-40.

52. Boudry G, Peron V, Le Huerou-Luron I, Lalles JP, Seve B. Weaning induces both transient and long-lasting modifications of absorptive, secretory, and barrier properties of piglet intestine. J Nutr. 2004;134:2256-62.

53. Ma X, Fan PX, Li LS, Qiao SY, Zhang GL, Li DF. Butyrate promotes the recovering of intestinal wound healing through its positive effect on the tight junctions. J Anim Sci. 2012;90:266-8.

54. Ushida K, Kameue C, Tsukahara T, Fukuta K, Nakanishi N. Decreasing traits of fecal immunoglobulin a in neonatal and weaning piglets. J Vet Med Sci. 2008;70:849-52.

55. Brandtzaeg P. The mucosal immune system and its integration with the mammary glands. J Pediatr. 2010;156:S8-15.

56. Kunisawa J, Kiyono $\mathrm{H}$. Immune regulation and monitoring at the epithelial surface of the intestine. Drug Discov Today. 2013;18:87-92.

57. Buckley RH. Humoral immunodeficiency. Clin Immunol Immunopathol. 1986:40:13-24

58. Cervantes JL, Hong BY. Dysbiosis and immune dysregulation in outer space. Int Rev Immunol. 2016;35:67-82.

59. Takahashi T, Nakagawa E, Nara T, Yajima T, Kuwata T. Effects of orally ingested Bifidobacterium longum on the mucosal IgA response of mice to dietary antigens. Biosci Biotechnol Biochem. 1998;62:10-5.

60. Umesaki $Y$, Setoyama $H$. Structure of the intestinal flora responsible for development of the gut immune system in a rodent model. Microbes Infect. 2000;2:1343-51

61. Schokker D, Zhang J, Zhang LL, Vastenhouw SA, Heilig HG, Smidt H, et al. Early-life environmental variation affects intestinal microbiota and immune development in new-born piglets. PLoS One. 2014;9:e100040.

62. Mourad FH, Hamdi T, Barada KA, Saade NE. Experimental colitis in rats induces de novo synthesis of cytokines at distant intestinal sites: role of capsaicin-sensitive primary afferent fibers. Eur Cytokine Netw. 2016;27:41-53.

63. Maeda H, Fujimoto C, Haruki Y, Maeda T, Kokeguchi S, Petelin M, et al. Quantitative real-time PCR using TaqMan and SYBR green for Actinobacillus actinomycetemcomitans, Porphyromonas gingivalis, Prevotella intermedia, tetQ gene and total bacteria. FEMS Immunol Med Microbiol. 2003;39:81-6

64. Layton A, McKay L, Williams D, Garrett V, Gentry R, Sayler G. Development of Bacteroides 165 rRNA gene TaqMan-based real-time PCR assays for estimation of total, human, and bovine fecal pollution in water. Appl Environ Microbiol. 2006;72:4214-24

65. Walker AW, Ince J, Duncan SH, Webster LM, Holtrop G, Ze X, et al. Dominant and diet-responsive groups of bacteria within the human colonic microbiota. Isme J. 2011:5:220-30.

66. Matsuki T, Watanabe K, Fujimoto J, Takada T, Tanaka R. Use of 165 rRNA genetargeted group-specific primers for real-time PCR analysis of predominant bacteria in human feces. Appl Environ Microbiol. 2004;70:7220-8.

67. Bartosch S, Fite A, Macfarlane GT, McMurdo ME. Characterization of bacterial communities in feces from healthy elderly volunteers and hospitalized elderly patients by using real-time PCR and effects of antibiotic treatment on the fecal microbiota. Appl Environ Microbiol. 2004;70:3575-81.

68. Huijsdens XW, Linskens RK, Mak M, Meuwissen SG, Vandenbroucke-Grauls CM, Savelkoul PH. Quantification of bacteria adherent to gastrointestinal mucosa by real-time PCR. J Clin Microbiol. 2002;40:4423-7.

69. Khafipour E, Li S, Plaizier JC, Krause DO. Rumen microbiome composition determined using two nutritional models of subacute ruminal acidosis. Appl Environ Microbiol. 2009:75:7115-24

70. Pieper R, Kroger S, Richter JF, Wang J, Martin L, Bindelle J, et al. Fermentable fiber ameliorates fermentable protein-induced changes in microbial ecology, but not the mucosal response, in the colon of piglets. J Nutr. 2012;142:661-7.

71. Collado-Romero M, Arce C, Ramirez-Boo M, Carvajal A, Garrido JJ. Quantitative analysis of the immune response upon Salmonella typhimurium infection along the porcine intestinal gut. Vet Res. 2010;41:23. 
72. Liu Y, Chen F, Odle J, Lin X, Jacobi SK, Zhu H, et al. Fish oil enhances intestinal integrity and inhibits TLR4 and NOD2 signaling pathways in weaned pigs after LPS challenge. J Nutr. 2012;142:2017-24.

73. Zhou XL, Kong XF, Lian GQ, Blachier F, Geng MM, Yin YL. Dietary supplementation with soybean oligosaccharides increases short-chain fatty acids but decreases protein-derived catabolites in the intestinal luminal content of weaned Huanjiang mini-piglets. Nutr Res. 2014;34:780-8.

74. Villodre Tudela C, Boudry C, Stumpff F, Aschenbach JR, Vahjen W, Zentek J, et al. Down-regulation of monocarboxylate transporter 1 (MCT1) gene expression in the colon of piglets is linked to bacterial protein fermentation and pro-inflammatory cytokine-mediated signalling. Br J Nutr. 2015;113:610-7.

Ready to submit your research? Choose BMC and benefit from:

- fast, convenient online submission

- thorough peer review by experienced researchers in your field

- rapid publication on acceptance

- support for research data, including large and complex data types

- gold Open Access which fosters wider collaboration and increased citations

- maximum visibility for your research: over $100 \mathrm{M}$ website views per year

At BMC, research is always in progress.

Learn more biomedcentral.com/submissions 